\title{
InCompatibilidade Física de Misturas entre HeRbicidas E INSETICIDAS $^{1}$
}

\author{
Physical Incompatibility of Herbicide and Insecticide Mixtures
}

PETTER, F.A. ${ }^{2}$, SEGATE, D. ${ }^{3}$, PACHECO, L.P. ${ }^{2}$, ALMEIDA, F.A. ${ }^{2}$ e ALCÂNTARA NETO, F. ${ }^{2}$

\begin{abstract}
RESUMO - Objetivou-se, com este trabalho, avaliar a interação física entre misturas em tanque de diferentes classes de defensivos agrícolas. O experimento foi conduzido no laboratório de Química da Universidade do Estado de Mato Grosso, no período de junho a agosto de 2010. Os tratamentos foram constituidos pelas misturas de seis herbicidas (glyphosate SC, glyphosate WG, lactofen CE, fomesafen SC, haloxifop-R CE e fluazifop-pbutil $\mathrm{EW}$ ) com seis inseticidas (methomyl CS, clorpirifós $\mathrm{CE}$, teflubenzuron SC, triflumuron SC, cipermetrina CE e tiametoxam + lambda-cialotrina SC) na ausência e presença de dois redutores de $\mathrm{pH}$ (ácido pirolenhoso e ácido bórico), com quatro repetições. Utilizou-se escala de 1 a 5, visando avaliar o grau de incompatibilidade, em que 1 é a separação imediata da mistura e recomenda-se não aplicar e 5 é a homogeneidade das misturas. As maiores incompatibilidades fisicas nas misturas de herbicidas e inseticidas foram observadas na presença dos herbicidas glyphosate na formulação WG e lactofen CE. O ácido pirolenhoso e o ácido bórico demonstraram ser boas alternativas, como redutores de $\mathrm{pH}$, no preparo de calda de pulverização com misturas de herbicidas e inseticidas. Devem-se evitar misturas em tanque de glyphosate na formulação SC + clorpirifós $\mathrm{CE}$ e lactofen $\mathrm{CE}+$ clorpirifós $\mathrm{CE}$.
\end{abstract}

Palavras-chave: mistura em tanque, floculação, precipitação, formulação.

\begin{abstract}
The objective of this study was to evaluate the physical interaction between simulated tank mixtures of different classes of pesticides. The experiment was conducted at the Chemistry Laboratory of the University of Mato Grosso, Brazil, from June to August 2010. The treatments consisted of mixtures of six herbicides (glyphosate $S C$, glyphosate WG, lactofen CE, fomesafen SC, haloxifop-R CE, and fluazifop-p-butyl EW) with six types of insecticide (methomyl CS, clorpirifos $C E$, teflubenzuron $S C$, triflumuron $S C$, cipermetrin $C E$, and tiametoxam + lambda-cialotrin SC) in the absence and presence of two $\mathrm{pH}$ reducers (pyroligneous acid and boric acid) with four replications. A scale from 1 to 5 was used to evaluate the degree of mismatch, where 1 is immediate separation of the mixture (which is recommended not to apply), and 5 is homogeneity of the mixtures. The major physical incompatibilities in the herbicide and insecticide mixtures were observed in the presence of glyphosate WG and lactofen SC. Pyroligneous acid and boric acid showed to be good alternatives as $\mathrm{pH}$ reducers in the preparation of sprays using the herbicide and insecticide mixtures. Tank mixtures of glyphosate formulation $S C$, clorpirifos $C E$, and lactofen $C E+$ clorpirifos $C E$ must be avoided.
\end{abstract}

Keywords: tank mixture, flocculation, rainfall, formulation.

\section{INTRODUÇÃO}

O Brasil destaca-se como um dos principais produtores mundiais de soja. A área ocupada por essa cultura na safra 2010/11 atingiu 24,16 milhões de hectares, com produtividade média de 72,22 milhões de toneladas (CONAB, 2011). Esse crescimento da área cultivada teve

Recebido para publicação em 4.7.2011 e aprovado em 12.11.2011.

2 Professor, Programa de Pós-Graduação em Agronomia - Fitotecnia, Universidade Federal do Piauí, Campus Prof ${ }^{\mathrm{a}}$. Cinobelina Elvas-CPCE/UFPI, 64900-000 Bom Jesus-PI, <petter@ufpi.edu.br>,<leandroppacheco@gmail.com>,<fernandes@ufpi.edu.br>, $<$ fneto@ufpi.edu.br>; ${ }^{3}$ Eng$^{\circ}-$ Agr $^{\circ}$., Universidade do Estado do Mato Grosso - UNEMAT, 78690-000 Nova Xavantina-MT, $<$ diegoagronomo@gmail.com>.

Planta Daninha, Viçosa-MG, v. 30, n. 2, p. 449-457, 2012 
impacto direto no setor de defensivos. A indústria de defensivos agrícolas começou o ano de 2010 com uma expectativa de crescimento de $10 \%$ no faturamento, sendo o consumo de inseticidas responsável por $21 \%$ do volume total consumido (SINDAG, 2010).

Muitos agricultores utilizam mistura em tanque de diferentes herbicidas e também de herbicidas com inseticidas e/ou outras classes de defensivos, com o objetivo de aumentar o espectro de ação e reduzir o número de aplicações.

Em algumas situações, as misturas entre herbicidas e inseticidas podem levar à ocorrência de interações, que se manifestam de forma aditiva, antagônica ou sinérgica, o que pode ou não prejudicar o controle, bem como produzir efeitos desconhecidos quanto à toxicologia (Nash, 1967; Gazziero \& Souza, 1993; Trezzi, 2005).

Com base nos relatos de Nash (1967), Marking (1985) e Calabrese (1991), as interações entre os pesticidas podem se classificar em: (a) efeito aditivo - a fitotoxicidade total resultante da combinação de dois ou mais defensivos é igual à soma dos efeitos de fitotoxicidade de cada produto aplicado isoladamente; (b) efeito sinergístico - a fitotoxicidade total resultante da combinação de dois ou mais pesticidas é maior do que a soma dos efeitos fitotóxicos de cada produto aplicado isoladamente; e (c) efeito antagonístico - a fitotoxicidade total resultante da combinação de dois ou mais defensivos é menor do que a fitotoxicidade de cada produto aplicado isoladamente.

A ocorrência de toxicidade às culturas e menor desempenho dos produtos em consequência da aplicação de misturas de diferentes classes de defensivos pode estar associada incompatibilidade física dessas misturas. Segundo Silva et al. (2007), o menor desempenho das misturas de defensivos pode ser resultado de qualquer incompatibilidade fisica entre os produtos, sendo esta usualmente causada pela formulação e suas interações, resultando em formação de precipitados, separação de fase e complexação. O problema de incompatibilidade pode ser minimizado, por exemplo, com o uso de adjuvantes e redutores de $\mathrm{pH}$ de calda. As moléculas, quando em solução, dissociam-se em íons, que podem ser de cargas negativas e positivas, podendo se ligar a outros íons presentes na solução. A resultante elétrica da dissociação das moléculas dos herbicidas varia em função do $\mathrm{pH}$ da solução; na maioria das vezes, para os herbicidas a carga iônica negativa aumenta com o incremento do $\mathrm{pH}$, o que faz com que moléculas de carga negativa se liguem às moléculas de carga positiva - a exemplo dos carbonatos presentes na maioria das águas consideradas duras (Vidal, 2002; Theisen \& Ruedell, 2004).

A tendência de utilizar misturas em tanque de diferentes classes de defensivos é uma prática quase que inevitável do ponto de vista econômico. Algumas misturas, dentro da mesma classe, vêm formuladas pelo fabricante e possuem registro no Ministério da Agricultura, Pecuária e Abastecimento. Ressalta-se que a mistura em tanque atualmente é de responsabilidade do agricultor, diferentemente do que acontecia entre os anos de 1995 e 2002, quando o Ministério exigia registros para as misturas.

Apesar de não se necessitar de registro, é imprescindivel o conhecimento prévio de possiveis misturas em tanque com produtos de diferentes ingredientes ativos e formulações, a fim de evitar possiveis danos à cultura e baixa eficiência deles.

Muitos trabalhos (York et al., 1991; York \& Jordan, 1992; Allen \& Snipes, 1995; Culpepper et al., 2001; Snipes \& Seifert, 2003; Petter et al., 2007) têm sido conduzidos ao longo dos anos sobre a interação entre herbicidas e inseticidas; contudo, as avaliações se direcionam para o efeito sobre o alvo biológico, avaliando-os em efeitos antagônicos, sinérgicos e aditivos. Esses efeitos se manifestam após a interação física dos defensivos, o que raramente é pesquisado, talvez em razão do elevado número de produtos disponíveis no mercado.

De maneira geral, as interações físicas estão associadas aos ingredientes inertes contidos nos defensivos (formulações, solventes), enquanto a interação química está associada à molécula dos defensivos. No entanto, deve-se ressaltar que, para que haja interação dos defensivos, primeiramente esta se dá de maneira física - em sua maioria, governada 
pelas características físico-químicas (solubilidade, pKa, Kow) dos defensivos, levando-os, por conseguinte, às interações químicas. Assim, a compatibilidade física dos defensivos é apenas o primeiro dos eventos que governam a estabilidade de calda e, consequentemente, os efeitos no alvo biológico. Este trabalho teve como objetivo avaliar em laboratório a incompatibilidade fisica de misturas de herbicidas e inseticidas usualmente utilizados na cultura da soja.

\section{MATERIAL E MÉTODOS}

O experimento foi conduzido no laboratório de Química da Universidade do Estado de Mato Grosso (UNEMAT), no período de junho a agosto de 2010.

O delineamento experimental utilizado foi de blocos inteiramente casualizados, em esquema fatorial $6 \times 6 \times 3$, sendo os tratamentos constituídos pelas misturas de seis herbicidas com seis inseticidas, na ausência e presença de dois redutores de $\mathrm{pH}$ (ácido pirolenhoso e ácido bórico) (Tabela 1), com quatro repetições, totalizando 108 tratamentos.

Para determinação do $\mathrm{pH}$ da água em condições normais, na presença dos redutores de $\mathrm{pH}$ e da calda final das misturas, foi utilizado um peagômetro. Foram utilizados dois volumes de béquer para fazer as caldas das misturas entre herbicidas + inseticidas, sendo usado o béquer de $250 \mathrm{~mL}$ para fazer a calda de produtos de baixa dosagem e o de $1.000 \mathrm{~mL}$ para fazer a calda de produtos com doses mais elevadas, simulando uma calda em condição de campo de $200 \mathrm{~L} \mathrm{ha}^{-1}$. As dosagens e o volume da calda foram proporcionais aos utilizados em campo; devido à baixa dosagem dos produtos, utilizaram-se seringas de 1,0 mL (uma para cada produto), visando dosá-los corretamente. Os produtos granulados foram pesados em uma balança analítica.

As misturas entre os produtos de diferentes classes foram feitas na seguinte ordem de adição dos componentes das misturas: na ausência de redutor de $\mathrm{pH}$ : água + herbicida + inseticida, medindo-se o $\mathrm{pH}$ antes e após a mistura; na presença de redutor de $\mathrm{pH}$ : água + redutor de $\mathrm{pH}+$ herbicida + inseticida, medindo-se também o pH antes e após a mistura.

Para reduzir o $\mathrm{pH}$ da água, que estava entre 6,0 e 7,8 em condições normais, para 5,0 , foram utilizados dois redutores de $\mathrm{pH}$, sendo o ácido pirolenhoso na dose de duas gotas para calda de $200 \mathrm{~mL}$ de água e três gotas para calda de $500 \mathrm{~mL}$ e o ácido bórico numa dosagem de 6 g para calda de $200 \mathrm{~mL}$ de água e $13,5 \mathrm{~g}$ para calda de $500 \mathrm{~mL}$. Para pesar o

Tabela 1 - Produtos e respectivas doses utilizadas no experimento, em Nova Xavantina-MT, 2010

\begin{tabular}{|c|c|c|c|}
\hline \multirow{2}{*}{ Nome comercial } & \multirow{2}{*}{ Nome técnico } & \multicolumn{2}{|c|}{ Dose ha ${ }^{-1}$} \\
\hline & & (g de i.a./e.a.)* & $(\mathrm{L} \text { ou kg de p.c. })^{* *}$ \\
\hline \multicolumn{4}{|c|}{ Herbicidas } \\
\hline Glifosato ${ }^{\circledR} 480 \mathrm{SC}$ & Glyphosate & $1.440,00$ & 3,00 \\
\hline Roundup $^{\circledR} 792,5 \mathrm{WG}$ & Glyphosate & $1.189,00$ & 1,50 \\
\hline Drible $^{(\mathbb{R}} 240 \mathrm{CE}$ & Lactofen & 120,00 & 0,50 \\
\hline Flex $^{\circledR} 250 \mathrm{SC}$ & Fomesafen & 175,00 & 0,70 \\
\hline Verdict-R ${ }^{\circledR} 124,7 \mathrm{CE}$ & Haloxifop-R-methyl & 62,35 & 0,50 \\
\hline Fusilade $^{(\mathbb{R}} 250 \mathrm{EW}$ & Fluazifop-P-butil & 400,00 & 1,60 \\
\hline \multicolumn{4}{|c|}{ Inseticidas } \\
\hline Methomex ${ }^{\circledR} 215$ CS & Methomyl & 150,50 & 0,70 \\
\hline Lorsban $^{\circledR} 480 \mathrm{CE}$ & Clorpirifós & 480,00 & 1,00 \\
\hline Cyptrin $\left.^{(}\right) 250 \mathrm{CE}$ & Cipermetrina & 30,00 & 0,12 \\
\hline Engeo Pleno $^{\circledR} 141 / 106 \mathrm{SC}$ & Tiametoxam + Lambda-cialotrina & $25,38+19$ & 0,18 \\
\hline Nomolt $^{\circledR} 150 \mathrm{SC}$ & Teflubenzurom & 7,50 & 0,05 \\
\hline Nomolt $^{\circledR} 150 \mathrm{SC}$ & Triflumurom & 14,40 & 0,03 \\
\hline
\end{tabular}

* g i.a./e.a. = gramas de ingrediente ativo/equivalente ácido; ** $\mathrm{L}$ ou $\mathrm{kg}$ de p.c. $=$ litros ou quilogramas de produto comercial. 
ácido bórico foi utilizada uma balança analítica em miligramas. As avaliações nos tubos de ensaio referentes às diferentes misturas foram realizadas nos seguintes intervalos de tempo: imediatamente após a mistura e 1, 5, 10 e 30 minutos depois. Observaram-se possiveis interações das misturas quanto a ocorrência de sobrenadante, precipitação, floculação ou mistura homogênea; em seguida, atribuíram-se notas em uma escala variando de 1 a 5 (Tabela 2), em que 1 significava separação imediata dos compostos e 5, estabilidade perfeita dos compostos.

Foram obtidas as estatísticas descritivas para as notas dos referidos tratamentos, em que as recomendações constantes na Tabela 2 são em função das médias de quatro repetições de cada tratamento.

Tabela 2 - Estabilidade das misturas entre as diferentes classes de defensivos agrícolas, em Nova Xavantina-MT, 2010

\begin{tabular}{|c|l|l|}
\hline Grau & \multicolumn{1}{|c|}{ Condição } & \multicolumn{1}{|c|}{ Recomendação } \\
\hline 1 & Separação imediata & Não aplicar \\
\hline 2 & Separação depois de 1 minuto & Não aplicar \\
\hline 3 & Separação depois de 5 minutos & Agitação contínua \\
\hline 4 & Separação depois de 10 minutos & Agitação contínua \\
\hline 5 & Estabilidade perfeita & Sem restrições \\
\hline
\end{tabular}

Fonte: Centro Brasileiro de Bioaeronáutica (CBB).

Diante desse grau de avaliação, foi recomendada com ou sem restrições - ou não recomendada - a aplicação das misturas quanto à compatibilidade física dos defensivos, deixando claro que essa compatibilidade é apenas uma das características, e a primeira a ser observada em misturas em tanque.

\section{RESULTADOS E DISCUSSÃO}

As misturas do herbicida glyphosate formulação 480 CS com os inseticidas methomyl, clorpirifós, cipermetrina, tiametoxam + lambda-cialotrina, teflubenzuron e triflumurom apresentaram comportamento de estabilidade de calda semelhante quando foram preparadas somente com água, água na presença de ácido pirolenhoso e água com ácido bórico (Tabela 3). Com exceção da mistura glyphosate + clorpirifós, todas as demais não apresentaram incompatibilidade física - observada pelo grau 5 , que é a estabilidade perfeita da mistura.
A mistura de glyphosate + clorpirifós apresentou grau 2 de incompatibilidade física logo após a mistura e se manteve ao longo das avaliações. Essa incompatibilidade de grau 2 pode ocasionar a precipitação dos produtos para o fundo do tanque do pulverizador, resultando em perdas consideráveis, uma vez que os precipitados geram concentração dos produtos muito maior em determinados momentos da aplicação. Nicolai \& Christoffoleti (2007) relatam a ocorrência de incompatibilidade caracterizada pela formação de precipitados ou aglutinados dentro do tanque de pulverização, que normalmente ficam retidos nos filtros ou nas pontas de pulverização, obstruindo-os. Esse efeito pode ser minimizado com a utilização de agentes dispersantes no momento de preparo da calda de pulverização e com a agitação constante da calda desde o seu preparo até a aplicação. Todavia, há o risco de possiveis efeitos fitotóxicos à cultura, como os relatados por Petter et al. (2007), que observaram toxicidade à cultura da soja com aplicação em mistura de glyphosate + clorpirifós. Essa toxicidade observada por esses autores devese possivelmente a uma interação físico-química provocada pela formulação dos produtos glyphosate, que, no caso, foi CE com clorpirifós SC. De acordo com Theisen \& Ruedell (2004), a maioria das incompatibilidades físicas e químicas é observada em misturas de produtos com formulações CE com PS, EW e SC.

Nas misturas do herbicida glyphosate formulação WG com os inseticidas methomyl, cipermetrina, teflubenzuron e triflumurom houve comportamento de estabilidade de calda semelhante quando preparadas com água, água na presença de ácido pirolenhoso e água com ácido bórico, observada pelo grau 5, que é a estabilidade perfeita dos compostos (Tabela 4).

Com exceção das misturas de glyphosate WG + clorpirifós e glyphosate WG + tiametoxam/ lambda-cialotrina, que apresentaram incompatibilidade física, observada pelo grau 1 a 3, as incompatibilidades das diferentes misturas mostraram comportamentos diferentes durante as avaliações. A incompatibilidade de grau 1, resultante da mistura de glyphosate $\mathrm{WG}+$ tiametoxam/lambda-cialotrina, ocasionou a floculação dos compostos, que resultou em pequena separação destes, os quais 
Tabela 3 - Estabilidade de calda de pulverização, de misturas do herbicida glyphosate (Glifosato 480 CS) com diferentes inseticidas, na ausência e presença de ácido pirolenhoso e ácido bórico, em Nova Xavantina-MT, 2010

\begin{tabular}{|c|c|c|c|c|c|c|c|c|c|c|c|c|c|c|c|}
\hline \multirow{3}{*}{$\begin{array}{c}\text { Tratamento } \\
\text { (herbicida }+ \text { inseticidas) }\end{array}$} & \multicolumn{5}{|c|}{ Água } & \multicolumn{5}{|c|}{ Ácido Pirolenhoso } & \multicolumn{5}{|c|}{ Ácido Bórico } \\
\hline & \multicolumn{15}{|c|}{ Estabilidade da calda no tempo (minutos) } \\
\hline & 0 & 1 & 5 & 10 & 30 & 0 & 1 & 5 & 10 & 30 & 0 & 1 & 5 & 10 & 30 \\
\hline Glyphosate + Methomyl & 5 & 5 & 5 & 5 & 5 & 5 & 5 & 5 & 5 & 5 & 5 & 5 & 5 & 5 & 5 \\
\hline Glyphosate + Clorpirifós & 5 & $2 *$ & 2 & 2 & 2 & 5 & $2 *$ & 2 & 2 & 2 & 5 & $2 *$ & 2 & 2 & 2 \\
\hline Glyphosate + Cipermetrina & 5 & 5 & 5 & 5 & 5 & 5 & 5 & 5 & 5 & 5 & 5 & 5 & 5 & 5 & 5 \\
\hline $\begin{array}{l}\text { Glyphosate + Tiametoxam/ } \\
\text { Lambda-cialotrina }\end{array}$ & 5 & 5 & 5 & 5 & 5 & 5 & 5 & 5 & 5 & 5 & 5 & 5 & 5 & 5 & 5 \\
\hline Glyphosate + Teflubenzuron & 5 & 5 & 5 & 5 & 5 & 5 & 5 & 5 & 5 & 5 & 5 & 5 & 5 & 5 & 5 \\
\hline Glyphosate + Triflumurom & 5 & 5 & 5 & 5 & 5 & 5 & 5 & 5 & 5 & 5 & 5 & 5 & 5 & 5 & 5 \\
\hline
\end{tabular}

* Precipitação - os valores correspondem aos graus de incompatibilidade descritos na Tabela 2.

Tabela 4 - Estabilidade de calda de pulverização, de misturas do herbicida glyphosate (Roundup WG) com diferentes inseticidas, na ausência e presença de ácido pirolenhoso e ácido bórico, em Nova Xavantina-MT, 2010

\begin{tabular}{|c|c|c|c|c|c|c|c|c|c|c|c|c|c|c|c|}
\hline \multirow{3}{*}{$\begin{array}{c}\text { Tratamento } \\
\text { (herbicida }+ \text { inseticidas) }\end{array}$} & \multicolumn{5}{|c|}{$\overline{\text { Água }}$} & \multicolumn{5}{|c|}{ Ácido Pirolenhoso } & \multicolumn{5}{|c|}{ Ácido Bórico } \\
\hline & \multicolumn{15}{|c|}{ Estabilidade da calda no tempo (minutos) } \\
\hline & 0 & 1 & 5 & 10 & 30 & 0 & 1 & 5 & 10 & 30 & 0 & 1 & 5 & 10 & 30 \\
\hline Glyphosate + Methomyl & 5 & 5 & 5 & 5 & 5 & 5 & 5 & 5 & 5 & 5 & 5 & 5 & 5 & 5 & 5 \\
\hline Glyphosate + Clorpirifós & 5 & 5 & $3 *$ & 3 & 3 & 5 & 5 & $3 *$ & 3 & 3 & 5 & 5 & 5 & 5 & 5 \\
\hline Glyphosate + Cipermetrina & 5 & 5 & 5 & 5 & 5 & 5 & 5 & 5 & 5 & 5 & 5 & 5 & 5 & 5 & 5 \\
\hline $\begin{array}{l}\text { Glyphosate + Tiametoxam/ } \\
\text { Lambda-cialotrina }\end{array}$ & $1^{* *}$ & 1 & 1 & 1 & 1 & $1^{* *}$ & 1 & 1 & 1 & 1 & $1^{* *}$ & 1 & 1 & 1 & 1 \\
\hline Glyphosate + Teflubenzuron & 5 & 5 & 5 & 5 & 5 & 5 & 5 & 5 & 5 & 5 & 5 & 5 & 5 & 5 & 5 \\
\hline Glyphosate + Triflumurom & 5 & 5 & 5 & 5 & 5 & 5 & 5 & 5 & 5 & 5 & 5 & 5 & 5 & 5 & 5 \\
\hline
\end{tabular}

* Precipitação, ** Separação e floculação - os valores correspondem aos graus de incompatibilidade descritos na Tabela 2.

flutuaram e desceram lentamente para o fundo. Já a incompatibilidade de grau 3, resultante da mistura de glyphosate WG + clorpirifós, pode ocasionar a precipitação dos produtos para o fundo do tanque de pulverização. Esse efeito pode ser minimizado com a agitação contínua da calda desde o seu preparo até a aplicação e o uso de ácido bórico como redutor de $\mathrm{pH}$, uma vez que seu uso eliminou a formação de precipitados (incompatibilidade física) em misturas de glyphosate WG + clorpirifós. O efeito da redução de precipitados pode ser explicado pelo comportamento de dissociação do herbicida glyphosate, que em $\mathrm{pH}$ ácido tem sua carga iônica negativa reduzida e, consequentemente, a adsorção a outras moléculas.

No entanto, não se recomenda a aplicação de glyphosate WG em mistura de tanque com o inseticida clorpirifós e tiametoxam/lambdacialotrina sem restrições, pois essas misturas podem provocar perdas consideráveis para o produtor. Alguns autores (Petter et al., 2007; Maciel et al., 2009) verificaram efeito fitotóxico de misturas envolvendo o herbicida glyphosate e inseticidas, porém não observaram redução significativa na produtividade da soja. Segundo Theisen \& Ruedell (2004), o efeito antagônico em misturas de defensivos pode ser consequência de incompatibilidade física destes, provocada pela mistura, por exemplo, de formulações WG com SC; além da redução dos niveis de controle, a toxicidade também é uma forma de efeito antagônico de misturas de defensivos. Todavia, em função das características físico-químicas dos produtos, normalmente a incompatibilidade fisica leva à incompatibilidade química, resultando nos efeitos tóxicos observados.

As misturas do herbicida lactofen formulação CE com os inseticidas methomyl, 
clorpirifós, cipermetrina, tiametoxam/lambdacialotrina, teflubenzuron e triflumurom apresentaram grau de incompatibilidade física quando preparadas com água, água na presença de ácido pirolenhoso e água com ácido bórico (Tabela 5). A incompatibilidade de grau 2 a 4 ocasionou mistura não homogênea, com tendência de decantação dos produtos. $\mathrm{Na}$ prática, esse efeito pode acarretar precipitações dos produtos para o fundo do tanque de pulverização, necessitando do uso de adjuvantes com ação dispersante e agitação contínua da calda, desde o seu preparo até a hora da aplicação. Os agentes dispersantes são considerados surfatantes e podem evitar a aglomeração das partículas através da redução das forças de coesão.

Diante disso, torna-se restrita a aplicação do herbicida lactofen $240 \mathrm{CE}$ em mistura de tanque com todos os inseticidas avaliados, pois a precipitação dos compostos pode gerar concentração muito maior em determinados momentos da aplicação. Corrêa \& Alves (2009) constataram que o herbicida lactofen aplicado isoladamente e em mistura com chlorimuronethyl, imazethapyr e haloxyfop-methyl provocou intoxicação inicial às plantas de soja, com posterior recuperação aos 27 dias após aplicação. A mistura de lactofen $240 \mathrm{CE}+$ methomyl na presença de ácido pirolenhoso reduz o efeito da incompatibilidade física normalmente ocorrida. O ácido pirolenhoso pode ser uma boa alternativa para minimizar os efeitos dessas misturas e potencializar o uso de diferentes classes de defensivos.

O preparo de calda utilizando o herbicida fomesafen formulação $250 \mathrm{SC}$ em misturas com os inseticidas methomyl, cipermetrina, tiametoxam/lambda-cialotrina, teflubenzuron e triflumurom não apresentou incompatibilidade física, ou seja, houve estabilidade perfeita da calda de pulverização, independentemente do uso ou não de redutores de $\mathrm{pH}$, caracterizada pelo grau 5 de estabilidade da calda (Tabela 6). Contudo, a mistura de fomesafen + clorpirifós apresentou incompatibilidade fisica quando preparada com água na presença de ácido bórico e ácido pirolenhoso -

Tabela 5 - Estabilidade de calda de pulverização, de misturas do herbicida lactofen (Drible $240 \mathrm{CE}$ ) com diferentes inseticidas, na ausência e presença de ácido pirolenhoso e ácido bórico, em Nova Xavantina-MT, 2010

\begin{tabular}{|c|c|c|c|c|c|c|c|c|c|c|c|c|c|c|c|}
\hline \multirow{3}{*}{$\begin{array}{c}\text { Tratamento } \\
\text { (herbicida }+ \text { inseticidas) }\end{array}$} & \multicolumn{5}{|c|}{$\overline{\text { Água }}$} & \multicolumn{5}{|c|}{ Ácido Pirolenhoso } & \multicolumn{5}{|c|}{ Ácido Bórico } \\
\hline & \multicolumn{15}{|c|}{ Estabilidade da calda no tempo (minutos) } \\
\hline & 0 & 1 & 5 & 10 & 30 & 0 & 1 & 5 & 10 & 30 & 0 & 1 & 5 & 10 & 30 \\
\hline Lactofen + Methomyl & 5 & 5 & $3 *$ & 3 & 3 & 5 & 5 & 5 & $4 *$ & 4 & 5 & 5 & $3 *$ & 3 & 3 \\
\hline Lactofen + Clorpirifós & 5 & 5 & 3* & 3 & 3 & 5 & $2 *$ & 2 & 2 & 2 & 5 & $2 *$ & 2 & 2 & 2 \\
\hline Lactofen + Cipermetrina & 5 & 5 & $3 *$ & 3 & 3 & 5 & 5 & $3 *$ & 3 & 3 & 5 & 5 & $3^{*}$ & 3 & 3 \\
\hline $\begin{array}{l}\text { Lactofen + Tiametoxam/ } \\
\text { Lambda-cialotrina }\end{array}$ & 5 & 5 & $3 *$ & 3 & 3 & 5 & 5 & $3 *$ & 3 & 3 & 5 & 5 & $3 *$ & 3 & 3 \\
\hline Lactofen + Teflubenzuron & 5 & 5 & 5 & $4 *$ & 4 & 5 & 5 & 5 & $4 *$ & 4 & 5 & 5 & $3 *$ & 3 & 3 \\
\hline Lactofen + Triflumurom & 5 & 5 & $3 *$ & 3 & 3 & 5 & 5 & 5 & $4 *$ & 4 & 5 & 5 & $3 *$ & 3 & 3 \\
\hline
\end{tabular}

* Precipitação - os valores correspondem aos graus de incompatibilidade descritos na Tabela 2.

Tabela 6 - Estabilidade de calda de pulverização, de misturas do herbicida fomesafen (Flex 250 SC) com diferentes inseticidas, na ausência e presença de ácido pirolenhoso e ácido bórico, em Nova Xavantina-MT, 2010

\begin{tabular}{|c|c|c|c|c|c|c|c|c|c|c|c|c|c|c|c|}
\hline \multirow{3}{*}{$\begin{array}{c}\text { Tratamento } \\
\text { (herbicida }+ \text { inseticidas) }\end{array}$} & \multicolumn{5}{|c|}{ Água } & \multicolumn{5}{|c|}{ Ácido Pirolenhoso } & \multicolumn{5}{|c|}{ Ácido Bórico } \\
\hline & \multicolumn{15}{|c|}{ Estabilidade da calda no tempo (minutos) } \\
\hline & 0 & 1 & 5 & 10 & 30 & 0 & 1 & 5 & 10 & 30 & 0 & 1 & 5 & 10 & 30 \\
\hline Fomesafen + Methomyl & 5 & 5 & 5 & 5 & 5 & 5 & 5 & 5 & 5 & 5 & 5 & 5 & 5 & 5 & 5 \\
\hline Fomesafen + Clorpirifós & 5 & 5 & 5 & 5 & 5 & 5 & 5 & 5 & $4 *$ & 4 & 5 & 5 & $3 *$ & 3 & 3 \\
\hline Fomesafen + Cipermetrina & 5 & 5 & 5 & 5 & 5 & 5 & 5 & 5 & 5 & 5 & 5 & 5 & 5 & 5 & 5 \\
\hline $\begin{array}{l}\text { Fomesafen + Tiametoxam/ } \\
\text { Lambda-cialotrina }\end{array}$ & 5 & 5 & 5 & 5 & 5 & 5 & 5 & 5 & 5 & 5 & 5 & 5 & 5 & 5 & 5 \\
\hline Fomesafen + Teflubenzuron & 5 & 5 & 5 & 5 & 5 & 5 & 5 & 5 & 5 & 5 & 5 & 5 & 5 & 5 & 5 \\
\hline Fomesafen + Triflumurom & 5 & 5 & 5 & 5 & 5 & 5 & 5 & 5 & 5 & 5 & 5 & 5 & 5 & 5 & 5 \\
\hline
\end{tabular}

* Precipitação - os valores correspondem aos graus de incompatibilidade descritos na Tabela 2. 
caracterizada pelo grau 3 a 4 . Esse efeito acaba resultando em perdas durante a aplicação, pelo fato de a combinação não ser perfeita, gerando precipitação das moléculas no tanque de pulverização. No entanto, esse efeito negativo pode ser minimizado com a agitação contínua da calda desde o seu preparo até a aplicação ou com aplicação conjunta de agentes dispersantes. Na prática, essa mistura deve ser evitada, a fim de não proporcionar efeito tóxico à cultura.

O uso do ácido pirolenhoso e ácido bórico prejudicou a mistura de fomesafen $250 \mathrm{SC}+$ clorpirifós, com destaque para o último, que levou à ocorrência de precipitados com maior intensidade e em menor tempo.

As diferentes misturas envolvendo o herbicida haloxyfop-methyl formulação $\mathrm{CE}$ com os inseticidas methomyl, clorpirifós, cipermetrina, tiametoxam/lambda-cialotrina, teflubenzuron e triflumurom não apresentaram incompatibilidade física; ambas as misturas mostraram comportamento de estabilidade de calda semelhante, seja a calda de pulverização preparada somente com água, água na presença de ácido pirolenhoso ou água com ácido bórico (Tabela 7). A aplicação de haloxyfop-methyl em mistura de tanque com os inseticidas avaliados, seja na presença ou não de redutor de $\mathrm{pH}$, pode ser recomendada.

Outros trabalhos (Barroso et al., 2008; Corrêa \& Alves, 2009) já demonstraram a compatibilidade do herbicida haloxyfop-methyl com outros defensivos, não se verificando reduções na produtividade da soja, o que é um indicativo de que não houve problemas quanto à incompatibilidade física e química dos produtos. As misturas do herbicida fluazifop formulação EW com os inseticidas methomyl, tiametoxam/lambda-cialotrina, teflubenzuron e triflumurom não apresentaram incompatibilidade física quando preparada a calda de pulverização somente com água, água na presença de ácido pirolenhoso e água com ácido bórico (Tabela 8). Efeito contrário foi observado na mistura de fluazifop + clorpirifós

Tabela 7 - Estabilidade de calda de pulverização, de misturas do herbicida haloxyfop-methyl (Verdict-R CE) com diferentes inseticidas, na ausência e presença de ácido pirolenhoso e ácido bórico, em Nova Xavantina-MT, 2010

\begin{tabular}{|c|c|c|c|c|c|c|c|c|c|c|c|c|c|c|c|}
\hline \multirow{3}{*}{$\begin{array}{c}\text { Tratamento } \\
\text { (herbicida }+ \text { inseticidas) }\end{array}$} & \multicolumn{5}{|c|}{ Água } & \multicolumn{5}{|c|}{ Ácido Pirolenhoso } & \multicolumn{5}{|c|}{ Ácido Bórico } \\
\hline & \multicolumn{15}{|c|}{ Estabilidade da calda no tempo (minutos) } \\
\hline & 0 & 1 & 5 & 10 & 30 & 0 & 1 & 5 & 10 & 30 & 0 & 1 & 5 & 10 & 30 \\
\hline Haloxyfop-methyl + Methomyl & 5 & 5 & 5 & 5 & 5 & 5 & 5 & 5 & 5 & 5 & 5 & 5 & 5 & 5 & 5 \\
\hline Haloxyfop-methyl + Clorpirifós & 5 & 5 & 5 & 5 & 5 & 5 & 5 & 5 & 5 & 5 & 5 & 5 & 5 & 5 & 5 \\
\hline Haloxyfop-methyl + Cipermetrina & 5 & 5 & 5 & 5 & 5 & 5 & 5 & 5 & 5 & 5 & 5 & 5 & 5 & 5 & 5 \\
\hline $\begin{array}{l}\text { Haloxyfop-methyl + Tiametoxam/ } \\
\text { Lambda-cialotrina }\end{array}$ & 5 & 5 & 5 & 5 & 5 & 5 & 5 & 5 & 5 & 5 & 5 & 5 & 5 & 5 & 5 \\
\hline Haloxyfop-methyl + Teflubenzuron & 5 & 5 & 5 & 5 & 5 & 5 & 5 & 5 & 5 & 5 & 5 & 5 & 5 & 5 & 5 \\
\hline Haloxyfop-methyl + Triflumurom & 5 & 5 & 5 & 5 & 5 & 5 & 5 & 5 & 5 & 5 & 5 & 5 & 5 & 5 & 5 \\
\hline
\end{tabular}

Os valores correspondem aos graus de incompatibilidade descritos na Tabela 2.

Tabela 8 - Estabilidade de calda de pulverização, de misturas do herbicida fluazifop (Fusilade 250 EW) com diferentes inseticidas, na ausência e presença de ácido pirolenhoso e ácido bórico, em Nova Xavantina-MT, 2010

\begin{tabular}{|c|c|c|c|c|c|c|c|c|c|c|c|c|c|c|c|}
\hline \multirow{3}{*}{$\begin{array}{c}\text { Tratamento } \\
\text { (herbicida }+ \text { inseticidas) }\end{array}$} & \multicolumn{5}{|c|}{ Água } & \multicolumn{5}{|c|}{ Ácido Pirolenhoso } & \multicolumn{5}{|c|}{ Ácido Bórico } \\
\hline & \multicolumn{15}{|c|}{ Estabilidade da calda no tempo (minutos) } \\
\hline & 0 & 1 & 5 & 10 & 30 & 0 & 1 & 5 & 10 & 30 & 0 & 1 & 5 & 10 & 30 \\
\hline Fluazifop + Methomyl & 5 & 5 & 5 & 5 & 5 & 5 & 5 & 5 & 5 & 5 & 5 & 5 & 5 & 5 & 5 \\
\hline Fluazifop + Clorpirifós & 5 & 5 & 5 & 5 & 5 & 5 & 5 & 5 & $4 *$ & 4 & 5 & 5 & 5 & 5 & 5 \\
\hline Fluazifop + Cipermetrina & 5 & 5 & 5 & $4^{*}$ & 4 & 5 & 5 & 5 & 5 & 5 & 5 & 5 & 5 & 5 & 5 \\
\hline $\begin{array}{l}\text { Fluazifop + Tiametoxam/ } \\
\text { Lambda-cialotrina }\end{array}$ & 5 & 5 & 5 & 5 & 5 & 5 & 5 & 5 & 5 & 5 & 5 & 5 & 5 & 5 & 5 \\
\hline Fluazifop + Teflubenzuron & 5 & 5 & 5 & 5 & 5 & 5 & 5 & 5 & 5 & 5 & 5 & 5 & 5 & 5 & 5 \\
\hline Fluazifop + Triflumurom & 5 & 5 & 5 & 5 & 5 & 5 & 5 & 5 & 5 & 5 & 5 & 5 & 5 & 5 & 5 \\
\hline
\end{tabular}

* Precipitação - os valores correspondem aos graus de incompatibilidade descritos na Tabela 2. 
na presença de redutor de $\mathrm{pH}$ (ácido pirolenhoso) e fluazifop + cipermetrina somente na presença de água. De maneira geral, as diferentes misturas envolvendo o herbicida fluazifop $250 \mathrm{EW}$ e inseticidas podem ser utilizadas na prática, porém sempre com agitação contínua das misturas no tanque de pulverização até o momento da aplicação.

Silva et al. (2005) relatam que a fitotoxicidade de alguns herbicidas tem mostrado ser influenciada por alguns inseticidas, principalmente organofosforados ou metilcarbamatos. Esses autores afirmam que os inseticidas organoclorados não têm apresentado interações com herbicidas. A mistura em tanque de fluazifop + clorpirifós é prejudicada na presença de ácido pirolenhoso. Já a mistura de fluazifop + cipermetrina é altamente estável na presença de ácido pirolenhoso e ácido bórico.

Segundo Miller \& Butler Ellis (2000), a instabilidade de caldas de pulverização pode influenciar na qualidade da aplicação devido à interação entre as características dos líquidos a serem aplicados e os mecanismos de formação da pulverização, como vazão, formação, distribuição das gotas e padrão de distribuição volumétrico, o que resulta em tratamentos de baixa eficiência e aumento nos riscos de deriva e contaminações ambientais.

Entre as misturas testadas dos herbicidas com inseticidas, as maiores incompatibilidades foram observadas com os herbicidas glyphosate na formulação WG e lactofen $\mathrm{CE}$. De modo geral, os ácidos pirolenhoso e bórico mostraram-se boas alternativas de uso como redutor de $\mathrm{pH}$ nas misturas de herbicidas com inseticidas. Devem-se evitar misturas em tanque de glyphosate na formulação CS + clorpirifós, glyphosate WG + tiametoxam/ lambda-cialotrina e lactofen + clorpirifós.

A utilização de redutores de $\mathrm{pH}$ pode potencializar as misturas de diferentes classes de defensivos, seja pela redução de incompatibilidade ou pela estabilidade química das moléculas na calda, principalmente para herbicidas, que requerem $\mathrm{pH}$ em torno de 3 a 5, como paraquat, glyphosate e fluazifop, evitando a hidrólise delas (Vidal, 2002). Herbicidas acídicos, quando em solução de $\mathrm{pH}$ ácido, tendem a se dissociar menos, em função da predominância de neutralidade de cargas, o que pode ser determinado pela constante de ionização (pKa).

\section{LITERATURA CITADA}

ALLEN, R.; SNIPES, C. E. Interactions of foliar insecticides applied with pyrithiobac. Weed Technol., v. 9, n. 3, p. $512-517,1995$.

BARROSO, A. L. L. et al. Seletividade de associações herbicidas pós-emergentes em variedade de soja precoce. $\mathbf{R}$. Bras. Herbic., v. 7, n. 2, p. 36-42, 2008.

CALABRESE, E. J. Multiple chemical interactions Chelsea: Lewis Publishers, 1991. p. 13

COMPANHIA NACIONAL DE ABASTECIMENTO CONAB. Acompanhamento de safra brasileira: Grãos, 7ํㅜ Levantamento, Abr. 2011. Brasília: 2011. 54 p.

CORRÊA, M. J. P.; ALVES, P. L. C. A. Eficácia de herbicidas aplicados em pós-emergência na cultura da soja convencional e transgênica. Planta Daninha, v. 27, n. 4, p. 1035-1046, 2009.

CULPEPPER, A. S. et al. Effect of insecticides on clomazone absorption, translocation and metabolism in cotton. Weed Sci., v. 49, n. 1, p. 613-616, 2001

GAZZIERO, D. L. P.; SOUZA, I. F. Manejo integrado de plantas daninhas. In: ARANTES, N. E. et al. (Ed.). Cultura da soja nos cerrados. Piracicaba: Potafos, 1993. p. 183-208.

MACIEL, C. D. G. et al. Seletividade de cultivares de soja $\mathrm{RR}^{\circledR} 757$ submetidos a misturas em tanque de glyphosate + chlorimuron-Ethyl associadas a óleo mineral e inseticidas. Planta Daninha, v. 27, n. 4, p. 755-768, 2009.

MARKING, L. L. Toxicity of chemical mixtures. In: RAND, G. M.; PETROCELLI, S. R. Fundamentals of aquatic toxicology. (Eds). Washington DC: Hemisphere Publishing, 1985. p. 164-176.

MILLER, P. C. H.; BUTLER ELLIS, M. C. Effects of formulation on spray nozzle performance for applications from ground-based boom sprayers. Crop Protec., v. 19, n. 8, p. $609-615,2000$.

NASH, R. G. Phytotoxic pesticide interactions in soil. Agron. J., v. 59, n. 3, p. 227-230, 1967

NICOLAI, M.; CHRISTOFFOLETI, P. J. Interações entre glyphosate e adubos foliares sobre parâmetros agronômicos do herbicida. B. Inf. SBCPD, v. 15, n. 3, p. 39-43, 2007

PETTER, F. A. et al. Associações entre o herbicida glyphosate e inseticidas na cultura da soja Roundup Ready ${ }^{\circledR}$ Planta Daninha, v. 25, n. 2, p. 389-398, 2007. 
SINDICATO NACIONAL DA INDÚSTRIA DE

PRODUTOS PARA A DEFESA AGRÍCOLA - SINDAG. O setor de defensivos agrícolas no Brasil. 2010. Disponível em: $<$ http://www.sindag.com.br/>. Acesso em: 3 set. 2010

SILVA, J. F. et al. Herbicidas: absorção, translocação, metabolismo, formulação e misturas. In: SLVA, A. A.; SILVA, J. F. (Eds.). Tópicos em manejo de plantas daninhas Viçosa, MG: Universidade Federal de Viçosa, 2007. 367 p.

SILVA, A. A. et al. Aplicações seqüenciais e épocas e doses e aplicação de herbicidas em mistura com chlorpirifos no milho e em plantas daninhas. Planta Daninha, v. 23, n. 3, p. 527-534, 2005.

SNIPES, C. E.; SEIFERT, S. Influence of malathion timing on cotton (Gossypium hirsutum) response to pyrithiobac. Weed Technol., v. 17, n. 2, p. 266-268, 2003.
THEISEN, G.; RUEDELL, J. Tecnologia de aplicação de herbicidas - teoria e prática. Passo Fundo: 2004. 90 p.

TREZZI, M. M. et al. Eficácia de controle de plantas daninhas e toxicidade ao milho da mistura de foramsulfuron e Iodosulfuron isoladamente ou em associação com atrazine e/ ou clorpirifós. Planta Daninha, v. 23, n. 4, p. 653-659, 2005.

VIDAL, R. Ação dos herbicidas. Porto Alegre: 2002. 89 p.

YORK, A. C.; JORDAN, D. L. Cotton (Gossypium hirsutum) response to clomazone and insecticide combinations. Weed Technol., v. 6, n. 4, p. 796-800, 1992.

YORK, A. C.; JORDAN, D. L.; FRANS, R. E. Insecticides modify cotton (Gossypium hirsutum) response to clomazone. Weed Technol., v. 5, n. 4, p. 729-735, 1991 